\title{
La "nación vascongada" y sus luchas en el Potosí del siglo XVII. Fuentes de estudio y estado de la cuestión ${ }^{1}$
}

Jurgi Kintana Goiriena

Universidad del País Vasco

\begin{abstract}
Este artículo ofrece un estado de la cuestión sobre la historia de la colectividad vasca de Potosí en el siglo XVII, prestando especial atención al conflicto que se vivió en la década de 1620. La introducción resume brevemente el devenir de los vascos de Potosí y los violentos sucesos que los enfrentaron a otras colectividades de origen peninsular. A continuación se indican las fuentes primarias para investigar estos hechos, tanto a nivel archivístico como cronístico. El siguiente apartado examina la historiografía contemporánea, y presenta un balance crítico de lo escrito hasta el presente. Por último se ofrece una relación bibliográfica. El objetivo del artículo es facilitar un primer acercamiento a la cuestión, y servir de base a investigaciones posteriores.
\end{abstract}

\section{Introducción}

La Villa Imperial de Potosí (hoy en Bolivia), capital económica de las Indias en época colonial y una de las principales fuentes de ingresos para la Corona Castellana, suscitó fascinación desde el descubrimiento de su cerro minero en 1543. La riqueza argentífera que albergaba la convirtió en un destacado núcleo de actividades humanas, atrayendo a innumerables personas a su alrededor. Así, sobre aquella fría y árida cumbre de más de cuatro mil metros creció una de las mayores urbes del mundo: a principios del siglo XVII se jactaba Potosí de contar con cien mil almas. Organizaciones, instituciones y formas de relación de todo tipo se crearon a partir de la explotación minera. Todo ello hizo de la historia de Potosí tan rica como su cerro; y ya, desde los tiempos de la conquista, la encontramos mencionada en crónicas, historias y anales, actividad narrativa que ha continuado hasta nuestros días. Un somero repaso de la historiografía contemporánea sobre Potosí nos revela que su sistema de producción ha dado pie a infinidad de trabajos: la "mita", la situación de los indígenas, la economía y el gobierno colonial, las tecnologías minero-metalúrgicas, los intercambios comerciales o los efectos internacionales de la circulación de

1 Artículo traducido, corregido y aumentado por el autor a partir del trabajo original en lengua vasca. 
riquezas. La prosperidad de la villa potosina ha proporcionado la documentación - relativamente abundante - necesaria para realizar todos estos estudios, amén de varias biografías sobre algunos de sus personajes ilustres. La Casa de la Moneda de Potosí, asimismo, es fuente destacada en trabajos de numismática.

Entre los temas relacionados con el Potosí colonial se encuentra la historia de su "nación" o colectividad vasca. ${ }^{2}$ Instalada ya a mediados del siglo XVI, gozó de un especial protagonismo en la primera mitad de la centuria siguiente.

Efectivamente, la explotación minera proporcionó a los vascos gran poder económico y político. La colectividad vasca, formada a comienzos del siglo XVII por unas ochenta familias, se adueñó de un gran número de minas y de "ingenios" para la extracción de plata. Gracias a sus productivas explotaciones, los azogueros vascos obtuvieron cuantiosas ganancias. Sin embargo la extracción de plata requería azogue (mercurio), monopolio de la Corona, que por falta de capital inicial, frecuentemente, no podía pagarse al momento y se fiaba. La Corona prefería que los dueños de minas e ingenios adeudaran a las cajas reales, a detener las extracciones, de las que se sacaba el sustancioso quinto real (el 20\% de la producción de plata). Las deudas solían saldarse a plazos. Es así que mediante este sistema de endeudamiento, las minas producían, el Rey obtenía sus quintos y muchos vascos se enriquecían. Tras el poder económico venía el político: los cargos municipales ("oficios") eran vendidos por la Corona a alto precio, cantidad que sólo los más acaudalados podían satisfacer. En Potosí, los vascos opulentos, acapararon la mayoría de oficios del cabildo, haciendose con el poder político de la villa. Sin embargo, tampoco se solía cubrir la totalidad del importe por estos cargos. Por tanto los vascos pudientes de Potosí, como era frecuente en el sistema económico de la Monarquía Hispánica y en general en el juego político-económico del Antiguo Régimen, compaginaban su poder con deudas a la Corona.

2 En la Edad Moderna la palabra "nación" solía utilizarse en el sentido de colectividad. Así podemos encontrar expresiones como "nación india", "nación castellana", "nación criolla" o "nación extremeña". En lo que respecta a la colectividad vasca se le aplicaba el nombre de "nación vascongada", "nación vizcaína" o la más cultista de "nación cantábrica" (cf. Zaballa, Ana de: "Los vascos en México a través de los sermones de la Cofradía de Aránzazu”, en Álvarez-Gila, Oscar et al. (ed.), Emigración y redes sociales de los vascos en América, Vitoria, 1996, pág. 470). Esa colectividad, normalmente incluía a alaveses, guipuzcoanos, vizcaínos y navarros (colándose en ocasiones algunos vasco-franceses y bearneses entre estos últimos) y a veces también a los habitantes de las Cuatro Villas (Castro Urdiales, Laredo, Santander y San Vicente de la Barquera). 
Sin embargo no toda la población de Potosí aceptaba de buen grado la posición que los vascos detentaban en la villa. Y es que el oligopolio vasco, posibilitaba numerosos abusos de poder. Asimismo, desde principios de siglo, había tensiones sociales de diverso tipo entre vascos y otras colectividades de origen peninsular, tensiones que iremos viendo mejor a lo largo de este trabajo. El conflicto se agravó en 1618 cuando el contador real se detuvo en Potosí para inspeccionar el monto de la deuda al fisco: los miembros del cabildo, vascos en su mayoría, debían una considerable cantidad a la Corona, tanto en concepto de azogue como por oficios. El contador suspendió a los deudores de sus cargos, decisión que estos impugnaron ante instancias superiores. Mientras sentencias y dictamenes, frecuentemente contradictorios, se sucedían y el tiempo pasaba, en la calle crecía el rencor hacia los vascos y aumentaba la esperanza de apartarlos del poder. En 1622 , al tiempo que algunos no vascos ocuparon puestos en el cabildo, un destacado miembro de la "nación vascongada" apareció asesinado. La detención de varios extremeños sospechosos del crimen, desató algaradas y luchas callejeras, enfrentamientos que se prolongaron casi a diario hasta 1625. Castellanos, extremeños, andaluces y otros formaron bando, y con el nombre de "vicuñas" acometieron a los vascos. Mientras la sufrida mayoría indígena de Potosí se mantenía al margen del conflicto, vascos y vicuñas se enzarzaban en duelos, represalias y asaltos a propiedades, provocando numerosos heridos y muertos en ambos bandos. Los vascos, inferiores en número, pronto tuvieron que replegarse, refugiarse en conventos o huir a otras ciudades. Asimismo en el seno del poco cohesionado bando vicuña se producían enfrentamientos internos. Diversos emisarios reales, trataron sin exito de solucionar el conflicto. Las luchas tomaron un nuevo cariz cuando una partida de vicuñas asaltó la casa del corregidor (favorable a los vascos), acto que fue considerado como ataque contra la autoridad real. Los soldados vicuñas, convertidos en sediciosos bandidos, fueron perseguidos por las autoridades y acabaron completamente derrotados. Tras el conflicto, los vascos volvieron a recuperar el poder.

Se trata, por tanto, de un tema lo suficientemente interesante como para merecer un estudio en profundidad. Con la esperanza de facilitar y promover esa labor investigadora hemos confeccionado el presente artículo. En el primer apartado se señalan las fuentes primarias de la época, tanto archivísticas como cronísticas. En el segundo, repasamos la historiografía desde el siglo XIX hasta nuestros días. El trabajo concluye con una relación bibliográfica. 


\section{Fuentes: archivos y escritos de la época}

\section{Archivos}

Los archivos constituyen la primera fuente de investigación, y como hemos indicado, la documentación referida a Potosí y los vascos es relativamente abundante. Los principales archivos que recogen información sobre este tema son los siguientes:

\section{a. Archivo de la Casa de la Moneda (ACM). Potosí}

Potosí, en su ACM, contiene el Libro de Juntas de la Hermandad de Nuestra Señora de Aránzazu en el que se inscribían las familias e individuos vascos. A través de este libro puede seguirse la evolución de la comunidad desde el año 1603, fecha en la que se creó la cofradía. Este material resulta imprescindible para estudiar las relaciones de parentesco y las uniones entre vascos. Al fin y al cabo la cohesión que mostraba esta colectividad se debió traducir al nivel familiar. Este archivo de Potosí contiene además interesantes documentos de otro tipo posiblemente catalogados. ${ }^{3}$

\section{b. Archivo General de Indias (AGI). Sevilla}

El Archivo General de Indias de Sevilla, dada su condición de archivo central, sobresale por el volumen de documentos que alberga. En él cabe destacar la sección V, Audiencia de Charcas en la que se encuentran numerosas cartas y memoriales dirigidos al Rey, exponiendo cada parcialidad (vascongados y vicuñas) quejas y reclamaciones. ${ }^{4}$ También está en

3 Marie Helmer tenía proyectado en 1960 la publicación de un Catálogo de las escrituras notariales del Archivo de la Casa de la Moneda en Potosí, con índice analítico parcial. t. I. (15721600), t. II. (1601-1650). Desafortunadamente no hemos podido dar con esta obra, si bien la primera parte del catálogo parece que estaba en prensa en 1960 (cf. Helmer, Marie: "Luchas entre vascongados y ‘vicuñas' en Potosí”, Revista de Indias, XX, n. ${ }^{\text { }}$ 81-82, Madrid, 1960, pág. 186).

4 Siguiendo las numerosas y significativas referencias que dan Alberto Crespo (en La guerra entre vicuñas y vascongados (Potosí, 1622-1625), Lima, 1956), y Jose Mari Esparza (en Potosí. Andanzas de un navarro en la guerra de las naciones, Tafalla, 1996, págs. 247-253), estos son los legajos de la Audiencia de Charcas del AGI que tratan el tema de los vascos de Potosí y sus luchas con los vicuñas: 2 , 19, 20, 22, 32, 36, 37, 52, 53, 55, 89, 124, 134, 415 y 419. Lo componen ordenanzas, cédulas reales, actas de cabildo, informes, cartas, memoriales, etcétera. Los legajos 53 y 134 son documen- 
la sección V la Audiencia de Lima donde hay algunos escritos concernientes a Potosí y a sus conflictos. ${ }^{5}$ La sección VI, Escribanía de Cámara de Justicia, guarda alguna que otra sentencia dictada contra los implicados en los enfrentamientos. ${ }^{6}$ Otra sección de necesaria consulta es la III, Contratación, que contiene los listados de pasajeros a Indias: ${ }^{7}$ aunque no ofrece información directamente relacionada con Potosí, resulta útil para rastrear el itinerario de los vascos que se asentaron en la villa. Sin embargo hay que tener en cuenta que a pesar de estar obligados a inscribirse antes de embarcar hacia el Nuevo Mundo no todos lo hacían. ${ }^{8}$ En cualquier caso disponemos de un inventario de los escritos relacionados con Potosí que se hallan en el AGI. ${ }^{9}$

\section{c. Archivo Nacional de Bolivia (ANB). Sucre}

El Archivo Nacional de Bolivia concentra la información relativa a los sucesos de Potosí en la sección Audiencia de La Plata (también llamada Audiencia de Charcas). En ella pueden encontrarse documentos de diverso tipo: libros de acuerdos (Acuerdos de Potosí), cartas, expedientes

\footnotetext{
tos de especial relevancia, pues contienen sendos informes dirigidos al Rey, el primero escrito por vascos (llamado Relación "B") y el segundo por castellanos (llamado Relación "A"). Fernando Serrano (en Vascos y extremeños en el Nuevo Mundo durante el siglo XVII: un conflicto por el poder, Mérida, 1993) dentro de la misma Audiencia de Charcas (del AGI), añade los legajos 114, 116 y 117 al tratar el conflicto menos violento y algo posterior a las luchas de Potosí, que se dio entre las élites extremeñas y vascas de Charcas en la década de 1630.

5 Dentro de la Audiencia de Lima, Esparza (en Potosí. Andanzas de un navarro...) cita los legajos 40 y 67; Crespo (en La guerra entre vicuñas y vascongados...) el 35, 40, 97, 155 y 156.

6 En la sección Escribanía de Cámara de Justicia Crespo (en La guerra entre vicuñas y vascongados..., pág. 71) cita el legajo 1188.

7 Ese listado se está publicando en la obra Catálogo de pasajeros a Indias, s. XVI, XVII, XVIII, habiéndose concluído el período 1509-1599: Bermúdez, C.: Catálogo de pasajeros a Indias, s. XVI, XVII, XVIII, vols. I-III (1509-1559), Sevilla, 1940-1946; y Galbis, Carmen: Catálogo de pasajeros a Indias, s. XVI, XVII, XVIII, vols. IV-VII (1560-1599), Madrid, 1980-1986. La lista de viajeros navarros inscritos en Contratación entre 1511 y 1599 también está publicada en DomínguezFernández, Enrique: "Pasajeros navarros a Indias en el siglo XVI", Principe de Viana. Segundo Congreso General de Historia de Navarra. Conferencias y Comunicaciones sobre América, Anejo 13, Pamplona, 1991, págs. 293-310. Aunque en esta última lista falta al menos la referencia de un navarro, la correspondiente a Miguelico de Çeruco (Contratación, 5267, n. 2, R. 6) que menciona Esparza en Potosí. Andanzas de un navarro..., pág. 247.

8 En el caso concreto de los vascos residentes en Potosí, Esparza (en Potosí. Andanzas de un navarro..., nota 13, pág. 247) constata que la mayoría no dio su nombre en Sevilla.

9 Vázquez-Machicado, José: Catálogo de documentos referentes a Potosí en el Archivo General de Indias de Sevilla, Potosí, 1964.
} 
judiciales (autos, pedimentos,...), etcétera. En total noventa y cuatro documentos - casi mil páginas - que contienen información significativa sobre el conflicto entre vascos y vicuñas. Todos estos documentos están ordenados y catalogados en el trabajo de Gunnar Mendoza. ${ }^{10}$ Por tanto, prácticamente todas las fuentes del ANB relativas a las luchas se encuentran localizadas y listas para ser investigadas (ver más adelante el apartado 2 y la bibliografía). Por contra, la documentación sobre los vascos, previa como posterior a los enfrentamientos, está por estudiar.

\section{d. Otros archivos}

Dentro de los tres archivos principales con material sobre Potosí y los vascos, hemos indicado algunas secciones y legajos de interés siguiendo las investigaciones de varios historiadores. Sin duda habrá más documentos a la espera de ser descubiertos. Asimismo, en los tres archivos, aparte de datos específicos sobre nuestro tema, podemos encontrar amplia información referente al gobierno, la administración y la economía de las Indias. Todo lo cual resulta práctico para conocer de primera mano el contexto en el que se movían los vascos en Potosí.

No hemos podido confirmar la existencia de fuentes sobre Potosí en otros archivos principales de América. Por contra, en España, deben citarse la Biblioteca Nacional, la Real Academia de la Historia y la Biblioteca del Palacio Real, las tres en Madrid. Todas ellas guardan documentos de interés. ${ }^{11}$ También es de consulta obligatoria el Archivo de la Real Chancillería de Valladolid, ya que se ocupaba de los procesos del norte de Castilla, incluidas las Provincias Vascas. En ella se encontrarán los documentos de jucios y sentencias relativos a los vascos que iban a América o que volvían de ella, así como los expedientes de hidalguía exi-

10 Mendoza, Gunnar: Guerra entre vascongados y otras naciones de Potosí, Potosí, 1954

11 Así dentro de la Biblioteca Nacional de España se encuentra el Memorial de la Villa de Potosí al Virrey D. Francisco de Toledo, manuscrito 3040, según nos informa Carmen Martín en "Vascos en Potosí: minas y mineros, según una fuente inédita de Arzáns y Vela", en Álvarez-Gila et al. (ed.), Emigración y redes sociales de los vascos en América, Vitoria, 1996, pág. 418. Y en la Real Academia de la Historia (RAH), en la Colección Vargas Ponce (CVP), Pablo Fernández-Albaladejo (en La crisis del Antiguo Régimen en Guipúzcoa, 1766-1833, Madrid, 1975, pág. 166) señala un informe enviado por los guipuzcoanos de Potosí a su Provincia: Relación de los alborotos de Potosí (RAH, CVP, t. 31, fol. 21 y siguientes). En la Biblioteca del Palacio se halla uno de los libros de Arzáns de Orsúa que citaremos más adelante. 
gidos para embarcarse hacia el Nuevo Mundo. ${ }^{12}$ En Sevilla, además del AGI, es interesante el archivo de su universidad.

Aunque más difíciles de localizar, varios archivos del País Vasco y España guardan cartas enviadas desde América, algunas de ellas desde Potosí. Hacer un seguimiento personal a los viajeros es otra manera de reconstruir la vida de los vascos instalados en la Villa Imperial. ${ }^{13}$ En este caso, los archivos históricos provinciales, municipales, particulares y diocesanos serán objeto de atención. ${ }^{14}$

\section{Crónicas de los siglos XVI-XVIII}

La segunda fuente principal de estudio sobre el tema es la cronística e historiografía de la época colonial. La prosperidad de los vascos de Potosí y la virulencia de las "guerras de naciones" fueron registradas por escritores del período. Entre éstos, es el potosino Bartolomé Arzáns de Orsúa y Vela (1676-1736), quien mayor fama ha logrado. Narró los hechos casi un siglo después de que ocurrieran, basandose en gran medida en los relatos recogidos a ancianos potosinos, es decir, fiándose de la memoria popular. Supuestamente también se valió de obras de historia anteriores, pero no consultó sino casualmente documentos originales. Además este autor, jugaba con la historia tanto como con su nombre, que a veces escribía como Martínez Arzáns y Vela, u Orsúa Arzáns y Vela. Por ello se le achaca ser excesivamente fantasioso y novelesco. Los investigadores que han contrastado la información documental con la dada por Arzáns comprueban frecuentes incongruencias. ${ }^{15}$ Así Helmer concluye que la obra del

12 Vicenta Cortés en "Fuentes documentales para la historia del País Vasco y América. Instrumentos de información”, en Álvarez-Gila et al. (ed.), Euskal Herria y el Nuevo Mundo. La contribución de los vascos a la formación de las Américas, Vitoria, 1996, págs. 459-481, trata de los archivos relacionados con el tema general de América y los vascos. No ofrece información detallada sobre temas específicos, como el de los vascos en Potosí, pero conviene consultar su obra como punto de partida.

13 Esto es, por ejemplo, lo que ha hecho Esparza en Potosí. Andanzas de un navarro..., quien ha seguido la correspondencia de Juan de Echarren y sus familiares, recogida en el Archivo Diocesano de Pamplona, C. 237, n. 3.

14 Particularmente, tenemos noticia de la existencia de una breve carta remitida desde Potosí por un vizcaíno a fines del siglo XVI. El escrito resulta significativo para ver el rápido ascenso vasco en el mundo minero y en el cabildo de la Ciudad Imperial. El texto original se halla en el Archivo de Simón Ruiz, leg. 196, sec. V “Cartas de América.”, Carta de Nicolás de Guevara, Potosí, 1595. La transcripción y el comentario de esta carta pueden encontrarse en Marie Helmer: "Un tipo social: "el minero' de Potosî’, Revista de Indias, XVI, Madrid, 1956, págs. 85-92.

15 Helmer: "Luchas entre vascongados... “, pág. 192; Esparza: Potosí. Andanzas de un navarro..., págs. $250-252$. 
autor potosino es de "valor casi nulo para el historiador" ${ }^{16}$ En cualquier caso citamos su Historia de la Villa Imperial de Potosí por las abundantes noticias que contiene y por tratarse de un autor ineludible, aunque sólo sea para criticarlo. ${ }^{17}$ Arzáns de Orsúa también dejó obras más breves de títulos y contenidos semejantes. ${ }^{18}$

Todas las crónicas mencionadas por Arzáns de Orsúa merecerían ser consultadas. Desgraciadamente hoy no constan en ningún archivo ni biblioteca, y la única reseña que disponemos de ellas es la realizada por el propio Arzáns. Por tanto pudiera tratarse de un registro de autoridades meramente ficticio. En cualquier caso recogemos sus referencias tal como las consigna Mendoza: ${ }^{19}$

Tendríamos para empezar una Relación de las guerras civiles de Potosí, para el católico rey Felipe IV, manuscrito de unas quinientas páginas supuestamente redactado durante el conflicto por el agustino vasco Juan de Medina. El capitán vicuña Pedro Méndez (?-1631) habría dejado inconclusa una Historia Potosina. Bartolomé de Dueñas, el colegial de San Cristóbal de la ciudad de la Plata José Velázquez (?-1675) y el maestro doctor Diego de Guillestegui colegial de San Juan de la Plata, serían cada uno autores de una respectiva Historia de Potosí, escritas las dos últimas en verso castellano. Un tal Juan Sobrino, criollo que habría participado en las luchas, primero en el bando vicuña y después como delator, presuntamente escribió sobre los enfrentamientos unas octavas del mismo título que las obras anteriores. Todos estos trabajos, estaban según Arzáns inéditos en su época. Por contra, el portugués Antonio de Acosta (¿Da Costa?) habría llegado a publicar en Lisboa su Crónica de Potosí escrita originalmente en portugués, aunque tampoco nos consta su existencia. Esta crónica, al poco tiempo de publicarse fue, según Arzáns, traducida al castellano por Juan Pasquier, andaluz de Potosí, sin que acabara su trabajo. Sobre los supues-

16 Helmer: "Luchas entre vascongados... “, pág. 192.

17 El manuscrito original se encuentra en la Biblioteca del Palacio Real en Madrid, y su autor aparece como Martínez Arzáns y Vela. La obra ha sido publicada en su integridad dos veces (y otras dos en ediciones parciales que omitimos): la primera bajo el nombre de Arzáns de Orsúa y Vela a cargo de Lewis Hanke y Gunnar Mendoza en 1965; la segunda como Martínez Arzáns y Vela a manos de la Biblioteca del Sesquicentenario de la República de Bolivia en 1975 (ver bibliografía).

18 Por ejemplo la obra publicada en 1970 con la introducción de Alberto Crespo y con el nombre de Arzáns de Orsúa (ver bibliografía). Asimismo, Martín (en "Vascos en Potosí: minas y mineros...") le confirma la autoría de las obras inéditas Extractos y noticias tomadas de una historia de Potosí y Crónica de los sucesos ocurridos en Potosí desde el año 1611, que serían resúmenes de la citada Historia de la Villa Imperial de Potosí.

19 Mendoza: Guerra entre vascongados..., págs. 15-17. 
tos trabajos de Juan de Villegas, partidario del bando vasco, de fray Francisco Xaramillo y del alférez vicuña Zafra, no nos han llegado ni los títulos. Encontrar cualquiera de estos trabajos sería un descubrimiento importante, aunque, como se ha indicado, la propia existencia de sus autores es cuestionada. El ANB parece que no conserva ninguna de estas presuntas obras..$^{20}$ Acaso haya más suerte en el ACM o en el AGI; y quizás el libro de Antonio de Acosta se encuentre en alguna biblioteca o archivo de Portugal.

La Crónica del Perú (1553) de Pedro Cieza de León es obra demasiado temprana para recoger la mayoría de los hechos que nos incumben. A pesar de ello da cuenta de los pormenores del descubrimiento del cerro de Potosí y de los primeros azogueros y comerciantes vascos que en él se instalaron. Uno de aquellos vascos propietarios de minas, Sancho de Madariaga escribió en 1610 dos obras sobre la extracción de la plata: Discurso donde se consideran (...) y Memoria y orden que se tiene (...). Estos manuscritos, conservados en la British Library, es posible que nada digan sobre la colectividad vasca, pero son ellas mismas elocuente muestra de la temprana importancia de los vascos en la minería potosina. Como nota, cabe indicar que Sancho de Madariaga se vio implicado en las posteriores luchas. Otro destacado vasco establecido en Potosí fue fray Vicente Bernedo, natural de Puente la Reina. La vida y milagros de este eremita piadoso produjo alguna publicación, aunque posiblemente esas hagiografías resulten tardías y un tanto periféricas para estudiar la vida vasca de Potosí. ${ }^{21}$ El destacado cronista Antonio de León-Pinelo (fines del XVI1660) entre las muchas obras escritas dejó una Historia de la Villa Imperial de Potosí. Descubrimiento y grandezas de su rico cerro publicada en Madrid en 1680.

Más curiosa es una obra anónima, supuestamente escrita en Potosí en 1624, en el momento de mayor intensidad del conflicto entre vascos y vicuñas, titulada: Tratado breve de una disputa y diferencia que hubo entre dos amigos, el uno castellano de Burgos y el otro vascongado en la

20 Es Gunnar Mendoza (en Guerra entre vascongados...) quien nos informa de todas estas obras, dándolas por perdidas. Mendoza que fue director del ANB durante las décadas de 1950-60 es de suponer que no halló ninguna de ellas en su archivo.

21 Nosotros hemos encontrado una obra de 1750 debida a Joseph Pérez de Beramendi: Thesoro escondido de el nobilíssimo Reyno de Navarra hallado entre la riqueza de el Perú, preciosa mina de virtudes descubierta en el Potosí, maravillosa vida y portentosa muerte, virtudes y milagros de el Venerable, penitente y Apostólico Siervo de Dios Padre Fray Vicente Bernedo (...), reeditado por Gabriel Martinez, Pedro Joseph Ezquerro, Pamplona, 1750. 
villa de Potosí, Reino del Perú. Esta obra no está exenta de problemas, pues podría tratarse de un apócrifo escrito en el siglo XIX. ${ }^{22}$ Hasta que la obra sea verificada habrá que considerarla con precaución. En caso de que no fuera una falsificación, estaríamos ante una obra apologética castellana, buena muestra de la ideología de la época. En ella se critican diversos aspectos de la sociedad vasca, como la hidalguía universal (especie de nobleza étnica que en teoría alcanzaba a todos los vascos), la presunta poca fidelidad que mostraban ante la Corona, sus herejías, etcétera. El libro no es un ideario especialmente novedoso ya que muchas de estas críticas eran frecuentes entre los polemistas peninsulares de aquel entonces, y en las propias posesiones americanas ya se conocían algunos libelos del mismo tono. ${ }^{23}$ En cualquier caso, esta obra refleja bien el ánimo que debió reinar en la Villa Imperial. Así, además de narrar algunos sucesos ocurridos durante el conflicto, puede ser muestra de ciertos argumentos que se usaban para tratar de legitimar ideológicamente a una u otra colectividad.

Exiten otras obras conservadas hasta nuestros días, que afortunadamente no presentan problemas respecto a su origen. La más destacada es la del licenciado Gabriel Gómez de Sanabria redactada en 1625 desde su cargo de fiscal de la audiencia de La Plata. Aunque sea algo favorable al bando vicuña parece ser que su Relación de las inquietudes y alborotos de la Villa Imperial de Potosí (...) describe con bastante objetividad los conflictos de los que fue testigo. El manuscrito original se conserva en la

22 Fue publicado por vez primera en Madrid el año 1876 con el sobretítulo de Castellanos y vascongados (recién acabada la segunda guerra carlista y cuando hervía la cuestión de la abolición de los Fueros vascos). Su anónimo editor (que firma "Z" y que según Mendoza podría esconder al americanista español Justo Zaragoza) la publicó sin dar apenas noticias sobre el manuscrito original. Asimismo dio a conocer el trabajo con declarado propósito polémico, mostrando una actitud favorable a la centralizadora unidad constitucional que se llevaba a cabo en aquel entonces. Todo ello hace sospechar a Mendoza de que acaso nos pudiéramos encontrar ante una falsificación (Guerra entre vascongados..., págs. 14, 18-19). Esta misma publicación la menciona Anselmo de Legarda (en Lo "vizcaíno" en la literatura castellana, San Sebastián, 1953, págs. 185, 329,452,515), quien aunque no profundiza en el contenido, identifica por su cuenta al editor también como Justo Zaragoza. Castellanos y vascongados es a su vez citado en una obra de Julio Caro-Baroja (en La hora navarra del XVIII. Personas, familias, negocios e ideas, Pamplona, 1969, págs. 19-20), que vuelve a reconocer tras la "Z" a Justo Zaragoza. Sin embargo ni Legarda ni Caro-Baroja hacen referencia alguna a la autenticidad de la obra (con lo que se entiende que no la cuestionan). El asunto merecería ser investigado.

23 Cabe mencionar el conocido escrito antivasco de comienzos del XVII Historia del búho gallego con las demás aves de España, anónimo atribuido al virrey del Perú conde de Lemos (obra que cita incluso el propio Tratado breve de Potosí). Parece que las posesiones de ultramar, siendo como eran territorios en los que concurrían colectividades de diverso origen peninsular, resultaron un lugar fecundo para las apologías de cada grupo. Los vascos no fueron en esto una excepción y publicaron en América algunas obras reivindicativas de su particularidad (por ejemplo los Discursos de la antigüedad de la lengua cántabra bascongada de Baltasar de Echave que viera luz en México en 1609). 
British Library, y el ANB posee una copia microfilmada. La segunda obra es la Coronica moralizadora del orden de San Agustin en Peru, con sucesos egemplares en esta monarquia, de fray Antonio de la Calancha. Este libro publicado en Barcelona entre 1638 y 1639 toca sólo superficialmente los conflictos de Potosí. Por último, se ha conservado una descripción anónima del Perú colonial que menciona muy brevemente la enemistad entre vascos y extremeños, aunque no trate específicamente los sucesos de Potosí. Un erudito ha identificado a ese anónimo escritor como el portugués de origen judío Pedro de León-Portocarrero. ${ }^{24}$

Estas han sido las obras de las que hemos tenido noticia y que pueden servir de fuente de investigación. Al igual que sucede con los archivos no sería de extrañar que hubiera más, pero creemos haber indicado las principales. No se han considerado otros objetos de estudio como podrían ser el arte y la arquitectura potosina del siglo XVII, que tal vez muestren alguna influencia vasca. ${ }^{25}$ La toponimia es otra área en la que tampoco hemos profundizado, siendo probable que haya en Potosí nombres de lugar derivados de antropónimos y topónimos vascos. Con esto, damos fin al apartado sobre fuentes.

\section{La historiografía contemporánea (siglos XIX-XX)}

A partir de las fuentes citadas se han realizado varios trabajos historiográficos en torno a los vascos de Potosí. Evidentemente, no todos los aspectos del devenir la colectividad vasca han merecido la misma atención. La "guerra" entre los "vascongados" y otras "naciones" agrupadas bajo el nombre de vicuñas ha sido el tema que ha producido trabajos más específicos y sustanciales. Y es que este conflicto constituye uno de los hechos más llamativos en la vida vasca de Potosí. A pesar de ser un hecho limitado en el tiempo, no es un episodio aislado y particular. Las causas que dieron pie a los sucesos bélicos están relacionadas con la evolución general de

24 El manuscrito original se encuentra en la Biblioteca Nacional de París. Hoy está publicado (ver en la bibliografía León-Portocarrero).

25 Juan de Contreras en su preve opúsculo Artífices vascos en América (Bilbao, 1952, págs. 16-18), destaca la labor de éstos en la construcción de obras eclesiásticas y civiles a lo largo de todo el Perú virreinal. Sin embargo entre las edificaciones que cita no figura ninguna del Potosí. Habría que comprobar si hubo alguna. La fuente referida por Juan de Contreras sobre esta cuestión es un artículo del arquitecto peruano Emilio Hearth-Terré: "Los artífices vascos en el Perú Virreinal", El Comercio, Lima, 1 de septiembre de 1948. 
la colectividad vasca de Potosí. Por cuanto los análisis realizados en torno a estas luchas abarcan amplios aspectos de la realidad de la villa. En consecuencia estos trabajos se nos presentan como los estudios existentes más completos sobre "la nación vascongada" en el Potosí del siglo XVII. Antes de abordar las investigaciones más recientes y especializadas, repasaremos la historiografía que incluye menciones esporádicas sobre los vascos de Potosí.

\section{Obras divulgativas y reseñas breves}

Resulta excepcional por su copiosidad la publicación Castellanos $y$ vascongados aparecida en 1876, al que hemos hecho mención anteriormente (ver nota 17). El misterioso editor " $Z$ " de este libro (probablemente Justo Zaragoza) recopilaba en él la citada obra Tratado breve de una disputa (...), añadiendo a continuación una serie de anexos compuestos de pasajes del trabajo de Arzáns de Orsúa y de otros. Todo ello se completaba con un prólogo y una conclusión polémica de la mano del editor en contra del régimen foral y de la singularidad vasca. ${ }^{26}$

Los siguientes trabajos sobre el tema fueron más sucintos. Finalizando el siglo XIX, el alavés Becerro de Bengoa daba cuenta de las luchas entre vascos y vicuñas en un breve artículo. ${ }^{27}$ Poco después, Antonio Artola presentaba en Madrid una tesis sobre el Potosí colonial. ${ }^{28}$ El boliviano Modesto Omiste, en su clásica obra sobre la historia de Potosí, explicaba los conflictos de la Villa Imperial, tocando superficialmente a los vascos. ${ }^{29}$ Salvador de Madariaga desde el exilio americano también los trataba en uno de sus libros de historia ${ }^{30}$ información que utilizaron Jon Bilbao

26 Debemos a Jose Mari Esparza la información relativa a esta obra, al permitirnos amablemente la consulta de un ejemplar en su poder.

27 Becerro de Bengoa, Ricardo: "Los bascongados y los vicuñas en Potosí", Euskal-Erria, XLIII, San Sebastián, 1900, págs. 580-584.

28 Artola y Guardiola, Antonio: Notas para una historia de la Villa Imperial de Potosí, tesis defendida en la Universidad Complutense de Madrid, Facultad de Filosofía y Letras. 1909. No hemos podido consultar esta obra inédita de Antonio Artola y Guardiola. Pero por sus apellidos suponemos que se trata de un autor de origen vasco, con lo que no sería de extrañar que en el estudio incluyera algunos datos sobre sus paisanos. Debemos la noticia de esta obra, al profesor Oscar Álvarez-Gila al que agradecemos asimismo la ayuda y apoyo ofrecidos para publicar este artículo.

29 Omiste, Modesto: Crónicas potosinas. Estadísticas, biográficas, notas históricas y políticas, La Paz, 1918.

30 Madariaga, Salvador de: Cuadro histórico de las Indias. Introducción a Bolivar, Buenos Aires, 1945. 
y William Douglass en su conocida obra sobre los vascos y el Nuevo Mundo Amerikanuak. ${ }^{31}$ De esta obra se sirvieron a su vez las diversas publicaciones en torno a los vascos y América aparecidas durante el quinto centenario: Duplá, Ruiz de Azúa, Andrés-Gallego, etc. ${ }^{32}$ Estas y otras menciones parecidas han constituido reseñas divulgativas más que investigaciones específicas. Además no muy útiles, ya que directa o indirectamente han seguido los discutibles trabajos de Arzáns de Orsúa.

Otros trabajos han sido realizados utilizando fuentes más directas. Así Caro-Baroja brevemente, y Fernández-Albaladejo en una pequeña mención se sirven de documentos de primera mano para reflejar los conflictos vividos por los vascos en Potosí ${ }^{33}$ Las biografías de José Berruezo e Ignacio Tellechea sobre la monja alférez Catalina de Erauso (1595-1635) son trabajos más especializados. ${ }^{34}$ No se centran en la cuestión de Potosí pero algo la tratan, debido a que Catalina estuvo durante cierto tiempo en la villa y participó en las luchas al lado de sus paisanos vascos. Mario Chacón y Brian Farrelly han estudiado respectivamente la iconografía y la vida de fray Vicente Bernedo, santón potosino de origen vasco según hemos visto. ${ }^{35}$ Ana María Presta en su reciente investigación sobre los encomenderos de La Plata, ofrece testimonios de algunos poseedores vascos de repartimientos indígenas, que estuvieron entre los primeros mineros de Potosí. ${ }^{36} \mathrm{El}$ libro de Lutgardo García-Fuentes, si bien no trabaja demasiado el tema que nos ocupa, algo dice de la actividad económica de los vascos de Potosí. ${ }^{37}$

31 Bilbao, Jon - Douglass, William A.: Amerikanuak: Basques in the New World, Reno (Nevada), 1975 (trad. cast. de Román Basurto: Amerikanuak: vascos en el nuevo mundo, Vitoria, 1984).

32 Duplá, Antonio: Presencia vasca en América 1492-1992. Una mirada crítica, San Sebastián, 1992; Ruiz de Azúa, Estíbaliz: Vascongadas y América, Madrid, 1992; Andrés-Gallego, José (coord.): Navarra y América, Colección las Españas y América, Madrid, 1992.

33 La fuente que usa Caro Baroja en La hora navarra..., es la ya citada obra Castellanos y vascongados. Fernández-Albaladejo (en La crisis del Antiguo Régimen...) utiliza el informe de los guipuzcoanos contenido en el RAH que hemos mencionado en el apartado de archivos.

34 Berruezo, José: Catalina de Erauso, San Sebastián, 1975; Tellechea, Ignacio: Doña Catalina de Erauso. La monja alférez, San Sebastián, 1992. Evidentemente no son estas las únicas obras sobre la famosa monja. Pero señalamos estas dos por ser relativamente recientes y porque contienen alguna información relacionada con nuestro tema.

35 Chacón, Mario: Iconografía de Vicente Bernedo, Potosí, 1981; Farrelly, Brian: Fray Vicente Bernedo, apóstol de Charcas, Salamanca, 1986.

36 Presta, Ana María: Los encomenderos de La Plata, Lima, 2000. Las referencias de Chacón, Farrelly y Presta nos han sido oportunamente facilitadas por el Comite de Redacción del Anuario de Estudios Americanos. También le debemos algunas sugerencias que han permitido mejorar el texto inicial, aunque, la responsabilidad del artículo resultante, con sus posibles errores y omisiones es, evidentemente, nuestra.

37 García-Fuentes, Lutgardo: Sevilla, los vascos y América, Bilbao, 1991. 
El prestigioso americanista Peter Bakewell, aunque tampoco profundiza en el tema de los vascos, los menciona en una obra y hace una interesante observación — que precisaremos más adelante- sobre el contexto económico en el que estalló el conflicto entre vascos y vicuñas. ${ }^{38}$

\section{Balance de los estudios específicos}

Cinco son los trabajos que abordan de lleno la cuestión de las luchas entre vascos y vicuñas. Estas obras incluyen además información sobre aspectos más generales de la vida vasca en Potosí. Se trata de tres libros y dos artículos, todos ellos de consulta imprescindible:

- Mendoza, Gunnar: Guerra entre vascongados y otras naciones de Potosí, Documentos del Archivo Nacional de Bolivia (1622-1641), Cuadernos de la Cultura Boliviana, Potosí, 1954, 77 págs.

- Crespo, Alberto: La guerra entre vicuñas y vascongados (Potosí, 1622-1625), prólogo de A. Miró, Tipografía Peruana, Lima, 1956, 171 págs.

- Helmer, Marie: "Luchas entre vascongados y 'vicuñas' en Potosí", Revista de Indias, XX, n 81-82, Madrid, 1960, págs. 185-195.

- Pérez-Alcalá, Rosario: "Vicuñas y vascongados: la lucha por el poder en Potosí en el siglo XVII", Ifigea, V-VI, 1989, págs. 207-215.

- Serrano, Fernando: Vascos y extremeños en el Nuevo Mundo durante el siglo XVII: un conflicto por el poder, Asamblea de Extremadura, Mérida, 1993, 116 págs.

El primer estudio, realizado por Gunnar Mendoza, se divide en tres partes. En la primera se recoge de forma ordenada y se comenta casi toda la bibliografía escrita desde el siglo XVII hasta 1945 sobre el tema ${ }^{39} \mathrm{El}$ apartado principal lo constituye el catálogo analítico de noventa y cuatro documentos del Archivo Nacional de Bolivia. Con él Mendoza nos pone a mano prácticamente la totalidad de papeles que puedan encontrarse en el ANB relativos a los conflictos de Potosí. La inestimable ayuda de este catálogo es completada con el listado de personas implicadas en las luchas,

38 Bakewell, Peter: Plata y empresa en el Potosí del siglo XVII: la vida y época de Antonio López de Quiroaga, Pontevedra, 1988.

39 De ella hemos tomado la mayoría de citas relativas a las crónicas y escritos del siglo XVII. La única obra que se le ha escapado a Mendoza, que nosotros sepamos, es la Historia de la Villa Imperial de Potosí. Descubrimiento y grandezas de su rico cerro de Antonio de León Pinelo, publicada en 1680 . 
indicando la ocupación y/o bando de cada una de ellas. Por último Mendoza ofrece un breve aunque compacto comentario de los hechos. En él presenta un esquema de los bandos en liza: el vasco, económica y políticamente poderoso, y el más heterogéneo de los vicuñas. Entre estos destacaban los "soldados", grupo social compuesto por aventureros medio vagabundos en busca de fortuna que se habrían revelado contra la riqueza y los abusos de poder de los vascos. Pero detrás, ocultos, instigando la lucha se encontrarían los vicuñas ricos, intentando desplazar a los vascos para ocupar ellos su lugar. Los ataques vicuñas habrían provocado el repliegue vasco en un primer momento y su posterior huida. Con el tiempo estos ataques habrían degenerado en bandolerismo y en alguna medida en alzamiento contra la autoridad. Los vicuñas ricos, alarmados, habrían decidido poner termino al conflicto, ahorcando a algunos soldados y logrando el perdón para el resto. Más adelante expondremos la crítica que se ha hecho a esta perspectiva.

Alberto Crespo, valiéndose de los archivos del AGI ofrece un pormenorizado relato histórico. Como dice Helmer "una narración sin erudición, pero brillante y colorida, que se lee como una novela de capa y espada". ${ }^{40}$ Por consiguiente una obra no muy analítica pero abundosa en datos e información. La conclusión sobre el conflicto que de ella se saca, es que las luchas, aunque aparentaran una forma de odios interregionales, habrían tenido mucho de pugna entre pobres (alineados en el bando vicuña) y ricos (vascos). Se ha achacado a Crespo hacer una interpretación excesivamente simple: el monopolio de poder a manos de una oligarquía y la existencia de pobres se mantuvo posteriormente sin que volviera a estallar conflicto alguno. ${ }^{41}$ Asimismo llamar "guerra" como hacen tanto Crespo como Mendoza a aquellas luchas resultaría excesivo y podría esconder la idea de que el conflicto, aunque Mendoza y Crespo lo digan con matices, habría sido una especie de alzamiento criollo contra la autoridad real, como si se tratara de un antecedente de las guerras de independencia de las colonias. Tanto Helmer como Pérez Alcalá niegan este extremo:42 los ataques en momento alguno se dirigieron contra la metrópolis o contra su autoridad,

40 Helmer: "Luchas entre vascongados ... “, pág. 185.

41 Helmer: "Luchas entre vascongados ... ", pág. 185. Helmer hace esta crítica extensible a Mendoza, opinión con la que discrepamos: Mendoza en momento alguno reduce el conflicto a meras luchas de pobres contra ricos, sino que señala claramente a los vicuñas poderosos como los movedores de la revuelta. Incluso respecto al simplismo de Crespo, parece que Helmer exagera un tanto.

42 Helmer: "Luchas entre vascongados ... ", pág. 193; Pérez-Alcalá: "Vicuñas y vascongados: la lucha ...”, pág. 207. 
circunscribiéndose a los bandos contendientes (el ataque a la casa del corregidor se habría producido por su favoritismo hacia los vascos, no por su calidad de representante del Rey). ${ }^{43}$

El artículo de Marie Helmer es una recesión de los dos libros que acabamos de comentar. Ya hemos mencionado algunas de las críticas que en ella se hacen. Como contribución positiva a la cuestión, Helmer plantea la existencia de una crisis económica como detonante de las luchas. Y es que si bien los odios venían de lejos, los ataques comenzaron tras conocerse en el año 1618 las deudas vascas al fisco. Esta colectividad debía grandes cantidades a la Corona, por endeudamiento de azogue y por oficios. El problema era consecuencia de la mala política fiscal de las colonias, pues no había créditos y la Corona se llevaba una exagerada porción de la producción de plata (el quinto), dificultando así el pago de las deudas. Además, según Helmer, antes de comenzar las hostilidades se produjo una crisis coyuntural en las minas de azogue, y la disminución de su producción afectó la de la plata. En torno a ese momento crítico tratarían las demás colectividades de suplantar a la vasca, dando inicio a las luchas. Aparte de este trabajo, Marie Helmer tiene un breve artículo relacionado con los inicios del ascenso vasco en Potosí a fines del siglo XVI. ${ }^{44}$ Asimismo tenía Helmer intención de editar un catálogo del ACM útil entre otras cosas para localizar la documentación relativa a los vascos de Potosí, aunque no hemos podido confirmar su publicación. ${ }^{45}$

El artículo de Rosario Pérez-Alcalá está realizado sobre los tres anteriores trabajos. En general coincide con las críticas de Helmer. No discute las dificultades económicas globales de las colonias, pero cuestiona que hubiera una crisis coyuntural previa al comienzo de los ataques. ${ }^{46}$ Sin embargo, el experto en historia económica Peter Bakewell, aparentemente sin conocer el artículo de Helmer, llega a conclusiones muy similares, esto es, que desde 1615, por tanto en los años previos al inicio del conflicto, la producción de plata potosina habría disminuido, enconando el odio contra

43 El equívoco de suponer que a los vicuñas les animaba el deseo de alzarse contra la metrópoli, no sólo es achacable a la visión mediatizada por preocupaciones contemporáneas que ha podido afectar a parte de la historiografía hispanoamericana, sino que las propias fuentes de nuestro caso pueden alimentar el error: los escritos vascos de la época, en su intento de desprestigiar al bando contendiente, no dudaron en acusar a los vicuñas de desafiar la autoridad del monarca, cuando evidentemente el conflicto era muy otro.

44 Se trata de la transcripción y comentario de la carta vizcaína enviada en 1595 que ya hemos mencionado en el apartado de fuentes (cf. Helmer: "Un tipo social: 'el minero'... “).

45 Ver nota 3.

46 Pérez-Alcalá: "Vicuñas y vascongados: la lucha ...”, pág. 208. 
los vascos ricos. ${ }^{47}$ Dejando a un lado la cuestión de la coyuntura económica, Pérez-Alcalá destaca la lucha por el poder subyacente tras las algaradas. Los principales impulsores de la revuelta serían por tanto los ricos vicuñas encubiertos, que tratarían de reemplazar a la oligarquía vasca. Para ello, claro esta, se habrían valido de tensiones anteriores, aunque en la última etapa del conflicto habrían perdido el control sobre ella.

Fernando Serrano, utilizando sobre todo las fuentes del A.G.I, nos ha ofrecido un nuevo libro. Desafortunadamente parece ignorar toda la historiografía anterior sobre el tema. Así deja de lado las perspectivas matizadas aportadas hasta ahora, y nos presenta el conflicto de Potosí reducido básicamente a una revuelta popular de los excluidos contra el asfixiante oligopolio vasco (descrito como "régimen de terror"). Aunque menciona el deseo de poder de las élites no vascas, aparentemente relega este factor a un segundo plano. En parte cabe achacar a la documentación utilizada por Serrano lo limitado de estas conclusiones. ${ }^{48}$ Por el contrario, en otras cuestiones relativas a nuestro tema, la aportación de Serrano resulta mucho más fecunda. Así merecen tenerse presentes las apreciaciones que hace sobre las mentalidades vasca y castellana. En el mismo sentido hay que subrayar la primacía de la colectividad extremeña que desvela Serrano en la formación y dirección del bando vicuña, así como el descubrimiento de tensiones entre las élites vascas y extremeñas una década después de los principales altercados de Potosí. ${ }^{49}$ Por último resulta muy sugestiva la idea que aporta de la relación entre las dinámicas universitarias y del imperio. Más exactamente la posibilidad de que el conflicto de Potosí fuera una trasposición de los frecuentes enfrentamientos entre "naciones" que se daban en las universidades peninsulares, enfrentamientos "llevados" allende la mar por las élites en ellas formadas. Los datos ofrecidos por Serrano para confirmar esta hipótesis no nos parecen concluyentes, pero en cualquier caso sus propuestas abren unas interesantes líneas de investigación para comprobar las relaciones entre

47 Bakewell: Plata y empresa..., pág. 36.

48 Serrano utiliza por fuente principal y sin dudar de su neutralidad el informe conocido como Relación "A" escrito por los castellanos (AGI, Charcas, 134); en cambio ni menciona la Relación "B" (AGI, Charcas, 53) escrita por los vascos, que cuanto menos serviría para contrastar opiniones. En general cabe decir que por el número de documentos del AGI consultados por Serrano su trabajo ha quedado rezagado respecto al realizado por Crespo en el mismo archivo.

49 Que nosotros sepamos ha sido Serrano el primero en señalar estas tensiones del año 1637. Si bien no tan espectaculares como los conflictos abiertos previos, son interesantes porque muestran que vascos y otras colectividades mantuvieron luchas de poder durante largo tiempo. 
el mundo universitario y la vida de las colectividades peninsulares en ultramar. $^{50}$

Aunque se trate de un obra inusual no podemos dejar sin mencionar un sexto trabajo en torno a los vascos de Potosí y sus conflictos. Nos referimos al libro Potosí. Andanzas de un navarro en la guerra de las naciones (Txalaparta, Tafalla, 1996, 260 págs.) de Jose Mari Esparza. En vez de un trabajo historiográfico convencional, se trata de una novela histórica construida con documentación original e información de la época. Todo ello se completa con la imaginación del autor en una narración de sabor antiguo y contenido realista. Así se nos cuenta la vida de un personaje histórico, Juan de Echarren, al que se siguen los pasos desde su pueblo natal en Navarra hasta el Alto Perú. Esta novela nos informa de los principales hechos ocurridos en Potosí además de ofrecernos un agradable relato. Si bien Esparza no desarrolla una hipótesis formal sobre las razones del conflicto, apunta al interés de los vicuñas ricos en suplantar a los vascos como principal causa de las luchas. Aparte del valor divulgativo de este trabajo, el investigador más especializado encontrará puntualmente señalados en él los documentos hallados por el autor en los archivos de España y América. Con lo que resulta una obra provechosa también para el ámbito académico. Todas esas referencias las hemos incluido en el apartado de fuentes.

No hemos encontrado sobre los vascos de Potosí bibliografía específica para la época posterior al conflicto de los años veinte. Al finalizar los enfrentamientos los vascos volvieron a detentar el poder, pero ignoramos los detalles. Esparza toca sólo superficialmente las décadas siguientes. Serrano, con documentación más precisa, descubre un brote de tensión entre élites extremeñas y vascas el año 1637 según hemos visto. Faltan en todo caso investigaciones para toda la época posterior. Lo llamativo de las luchas de bandos ha hecho que sea ese episodio particular el tema que ha acaparado toda la historiografía relativa a la vida de los vascos de Potosí.

50 Las luchas universitarias de Salamanca que menciona Serrano son estrictamente coetáneas a las de Potosí, no anteriores, y por consiguiente no pueden ser antecedentes de estas. Además Serrano no confirma que cabecillas vicuñas o vascos participaran durante su juventud en conflictos universitarios de ese tipo. Habría que comprobar, por tanto, este extremo. Existe otra posibilidad que nos ha sido señalada por el profesor Oscar Álvarez-Gila: pudiera suceder que la violencia entre "naciones" se iniciara en un determinado punto de la Monarquía, ya en Salamanca ya en Potosí, y que la expansión de la noticia provocara el estallido de conflictos análogos en otros puntos donde vascos y castellanos convivieran en tensión. No habría por tanto un antecedente universitario y una repetición años después en las Indias, sino una dinámica de redes que interactuaría simultáneamente a lo largo de toda la Monarquía Hispánica. Evidentemente, esta posibilidad no excluye la hipótesis de Serrano. 
Sin embargo, como apuntábamos en el apartado de las fuentes, además del conflicto podrían investigarse los primeros pasos de la colectividad vasca potosina, o su devenir tras los enfrentamientos, que debió seguir siendo bastante prospero. ${ }^{51}$ Sea como fuere, en tanto que carecemos por el momento de esos estudios, nuestro estado de la cuestión se ha centrado en el tema de las luchas.

\section{Conclusión}

Haciendo balance de las investigaciones precedentes, y ciñéndonos al conflicto entre vascos y vicuñas, podemos decir que en él se entremezclaron los siguientes elementos: el monopolio económico y político de los vascos; el consiguiente descontento que ello producía en las demás colectividades peninsulares (especialmente entre las más desfavorecidas); el deseo de los vicuñas ricos de suceder en el poder a los vascos; solidaridades y odios entre "naciones" (y su posible conexión con la universidad); la existencia de un nutrido grupo de "soldados" desocupados en la ciudad; problemas generales del sistema financiero de las colonias; una posible crisis económica coyuntural; y la excesiva corrupción de las instituciones. El interesado en el tema deberá tratar estas cuestiones.

Para finalizar cabe añadir que conflictos semejantes al de Potosí, con vascos de por medio, se repitieron en la América colonial más de una vez (por ejemplo el ocurrido en las minas de Laicacota o Izacota entre 1665-1671).52 Sería interesante investigar la influencia que todos estos sucesos tuvieron de cara a unir la colectividad vasca, dividida en su tierra de origen en varias unidades político-administrativas. Sospechamos que el desarrollo de la solidaridad comunitaria y la formación de un imaginario

51 Según un testimonio del año 1658 (ver "El viaje de Acarate du Biscay" en I. A. Leonard: Viajeros por la América Latina Colonial, México, 1992, págs. 116-129) Aránzazu llamaban al cerro de Potosí (haciendo referencia al santuario mariano homónimo sito en un alto del País Vasco), lo que probaría la importancia que todavía mantenían los vascos durante la segunda mitad del siglo XVII.

52 Los sucesos de Laicacota, como los de Potosí, han dado pie a algunas investigaciones. Pero en tanto que no conciernen directamente al tema de los vascos de Potosí, nos limitaremos a señalar un par de trabajos que puedan servir al lector curioso como punto de partida: Lohmann, Guillermo: El conde de Lemos, Virrey del Perú, Madrid, 1946, sobre todo las págs. 151-227; Maiza, Carlos - Oreja, José María: "Izacota: revuelta en una mina peruana (1665-1671)", Príncipe de Viana. Segundo Congreso General de Historia de Navarra. Conferencias y Comunicaciones sobre América, Anejo 13, Pamplona, 1991, págs. 343-351; también Esparza desarrolla el tema en su novela (Potosí. Andanzas de un navarro..., págs. 221-244). 
colectivo común en Vasconia en la Edad Moderna no es ajena a los intereses compartidos que desarrollaron los vascos en América. Pero estudios tan amplios necesitan que casos como el de Potosí sean mejor conocidos. Por consiguiente, esperemos que nuevas investigaciones aborden este tema de Potosí, que además de fascinante en sí mismo resulta a su vez enriquecedor para comprender el devenir general de los vascos y la historia del conjunto de la sociedad colonial.

\section{Bibliografía}

Hemos dividido la bibliografía en dos apartados. En el primero incluimos las obras antiguas comentadas a lo largo del artículo. Salvo excepciones no se encontrarán en él papeles de archivos. Para ese tipo de documentos puede dirigirse a los catálogos de Mendoza y VázquezMachicado. ${ }^{53}$ Las ediciones modernas de los libros antiguos han sido indicadas, en su caso, entre paréntesis tras los originales. El segundo apartado contiene la bibliografía y la historiografía contemporánea, limitada a las obras que tratan o tocan el tema de los vascos en Potosí. Las demás obras citadas en el texto o a pie de página no se recogen en esta bibliografía.

\section{Crónicas y obras antiguas}

Acosta, Antonio de: Crónica de Potosí (obra en portugués), Lisboa, s. XVII. (Supuesta obra citada por Arzáns de Orsúa. Presuntamente publicada pero perdida).

Anónimo: Tratado breve de una disputa y diferencia que hubo entre dos amigos, el uno castellano de Burgos y el otro vascongado, en la villa de Potosí, reino del Perú, 1624. El manuscrito original se encuentra supuestamente en una indeterminada biblioteca particular de Madrid. (Primera ed.: Z[aragoza, Justo] (ed.): Castellanos y vascongados. Tratado breve (...), Madrid, 1876, págs. 13-61).

Arzáns de Orsúa y Vela, Bartolomé: Anales de la Villa Imperial de Potosí, s. XVIII (ahora con prólogo de A. Crespo, Ministerio de Educación y Cultura / Biblioteca Popular Boliviana, La Paz, 1970).

Calancha, Antonio de la: Coronica moralizadora del orden de San Agustín en Perú, con sucesos egemplares en esta monarquia, Barcelona, 1638/1639.

53 Mendoza: Guerra entre vascongados...; Vázquez-Machicado: Catálogo de documentos... 
Cieza de León, Pedro de: La crónica del Perú, Sevilla, 1553 (ahora en Peisa, Lima, 1988).

Dueñas, Bartolomé de: Historia de Potosí, s. XVII. (Supuesta obra citada por Arzáns de Orsúa. Presuntamente inédita y perdida).

Gómez de Sanabria, Gabriel: Relación de las inquietudes y alborotos de la Villa Imperial de Potosí, y provincia de los charcas, sucecidos y continuados desde ocho de junio de mill y seiscientos y veinte y cinco (...). La Plata, 1625. Manuscrito. British Library. (Copia microfilmada en el ANB).

Guillestegui, Diego de: Historia de Potosí, s. XVII. (Supuesta obra citada por Arzáns de Orsúa. Presuntamente inédita y perdida).

León-Pinelo, Antonio de: Historia de la Villa Imperial de Potosí. Descubrimiento y grandezas de su rico cerro, Madrid, 1680.

[León-Portocarrero, Pedro de]: (Título desconocido, s. XVII. Ahora: Descripción del virreinato del Perú, crónica inédita de comienzos del siglo XVII, Lewin, B. (ed.), Rosario (Argentina), 1958; y: "Descripción anónima del Perú (1600-1615)", Leonard, I. A. (ed.), Viajeros por la América Latina colonial, Fondo de Cultura Económica, México, 1992, págs. 95-110).

Madariaga, Sancho de: Discurso donde se consideran las diferentes calidades que se crían en las vetas que tiene de plata el gran Cerro de Potosí y que será la causa de estas diferencias, y de la manera que se deben beneficiar cinforme sus calidades diferentes, 1610. Manuscrito, sloan 3055, pág. 6120, f. 7686. British Library.

Madariaga, Sancho de: Memoria y orden que se tiene de beneficiar los metales que se sacan del Cerro de Potosí en el ingenio de Sancho de Madariaga en Tarapaya y en los demás de dicha villa, 1610. Manuscrito, sloan 3055, pág. 6120, f. 7686. British Library.

Martínez Arzáns y Vela: Historia de la Villa Imperial de Potosí, s. XVIII. Manuscrito. Biblioteca del Palacio Real, Madrid (ahora Arzáns de Orsua y Vela, ed. y estudio preliminar de L. Hanke y L. G. Mendoza, Brown University Press, Providence (Rhode Island), 1965; y Martínez Arzáns y Vela, Bartolomé, Biblioteca del Sesquicentenario, Bolivia, 1975).

Medina, Juan de: Relación de las guerras civiles de Potosí, para el católico rey Felipe IV, s. XVII. (Supuesta obra citada por Arzáns de Orsúa. Presuntamente inédita y perdida).

Memorial de la Villa de Potosí al Virrey D. Francisco de Toledo, 3040 eskuizkribua, Biblioteca Nacional, Madrid.

Méndez, Pedro: Historia Potosina, s. XVII. (Supuesta obra citada por Arzáns de Orsúa. Presuntamente inédita y perdida).

Pasquier, Juan de: Historia de Potosí, s. XVII. (Supuesta obra citada por Arzáns de Orsúa como traducción al castellano de la Crónica de Potosí de Antonio de Acosta. Presuntamente inédita y perdida). 
Pérez de Beramendi, Joseph: Thesoro escondido de el nobilíssimo Reyno de Navarra hallado entre la riqueza de el Perú, preciosa mina de virtudes descubierta en el Potosí, maravillosa vida y portentosa muerte, virtudes y milagros de el Venerable, penitente y Apostólico Siervo de Dios Padre Fray Vicente Bernedo (...), reeditado por Gabriel Martinez, Pedro Joseph Ezquerro, Pamplona, 1750. Fundación Sancho el Sabio (Vitoria).

Relación de los alborotos de Potosí, Real Academia de la Historia (Madrid), Colección Vargas Ponce, t. 31, fol. 21 y ss.

Sobrino, Juan: Historia de Potosí, s. XVII. (Supuesta obra citada por Arzáns de Orsúa. Presuntamente inédita y perdida).

Velázquez, José: Historia de Potosí, s. XVII. (Supuesta obra citada por Arzáns de Orsúa. Presuntamente inédita y perdida).

Villegas, Juan de: (Título desconocido, s. XVII. Supuesta obra citada por Arzáns de Orsúa. Presuntamente inédita y perdida).

Xaramillo, Francisco: (Título desconocido, s. XVII. Supuesta obra citada por Arzáns de Orsúa. Presuntamente inédita y perdida)

Zafra: (Título desconocido, s. XVII. Supuesta obra citada por Arzáns de Orsúa. Presuntamente inédita y perdida)

\section{Bibliografía contemporánea}

Andrés-Gallego, José (coord.): Navarra y América, Colección las Españas y América, Mapfre, Madrid, 1992.

Artola y Guardiola, Antonio: Notas para una historia de la Villa Imperial de Potosí, tesis defendida en la Universidad Complutense de Madrid, Facultad de Filosofía y Letras. 1909.

Bakewell, Peter: Plata y empresa en el Potosí del siglo XVII: la vida y época de Antonio López de Quiroaga, Diputación Provincial de Pontevedra Departamento de Publicaciones, Pontevedra, 1988 (primera edición en inglés).

Becerro de Bengoa, Ricardo: "Los bascongados y los vicuñas en Potosí”, EuskalErria, XLIII, San Sebastián, 1900, págs. 580-584.

Bermúdez, C.: Catálogo de pasajeros a Indias, s. XVI, XVII, XVIII, vols. I-III (1509-1559), Consejo Superior de Investigaciones Científicas, Sevilla, 1940-1946.

Berruezo, José: Catalina de Erauso, San Sebastián, 1975.

Bilbao, Jon - Douglass, William A.: Amerikanuak: Basques in the New World, University of Nevada Press, Reno (Nevada), 1975 (trad. cast. de Román Basurto: Amerikanuak: vascos en el nuevo mundo, Servicio Editorial de la UPV-EHU, Vitoria, 1984). 


\section{LA “NACIÓN VASCONGADA” Y SUS LUCHAS EN EL POTOSÍ DEL SIGLO XVII}

Caro-Baroja, Julio: La hora navarra del XVIII. Personas, familias, negocios e ideas, Institución Principe de Viana, Pamplona, 1969.

Chacón, Mario: Iconografía de Vicente Bernedo, Casa Nacional de la Moneda, Potosí, 1981.

Contreras, Juan de (Marqués de Lozoya): Artífices vascos en América, Junta de Cultura de Vizcaya, Bilbao, 1952.

Cortés, Vicenta: "Fuentes documentales para la historia del País Vasco y América. Instrumentos de información", en Álvarez-Gila, Oscar et al. (ed.), Euskal Herria y el Nuevo Mundo. La contribución de los vascos a la formación de las Américas, Servicio Editorial de la UPV-EHU, Vitoria, 1996, págs. 459-481.

Crespo R., Alberto: La guerra entre vicuñas y vascongados (Potosí, 1622-1625), prólogo de A. Miró, Tipografía Peruana, Lima, 1956 (2. a ed., Colección Popular, La Paz, 1969).

Domínguez-Fernández, Enrique: "Pasajeros navarros a Indias en el siglo XVI", Principe de Viana. Segundo Congreso General de Historia de Navarra. Conferencias y Comunicaciones sobre América, Anejo 13, Pamplona, 1991, págs. 293-310.

Duplá, Antonio: Presencia vasca en América 1492-1992. Una mirada crítica, Gakoa, San Sebastián, 1992.

Esparza, Jose Mari: Potosí. Andanzas de un navarro en la guerra de las naciones, Txalaparta, Tafalla, 1996.

Farrelly, Brian: Fray Vicente Bernedo, apóstol de Charcas, Editorial San Esteban, Salamanca, 1986.

Fernández-Albaladejo, Pablo: La crisis del Antiguo Régimen en Guipúzcoa, 17661833: Cambio económico e historia, Akal, Madrid, 1975.

Galbis, Carmen: Catálogo de pasajeros a Indias, s. XVI, XVII, XVIII, vols. IV-VII (1560-1599), Ministerio de Cultura, Madrid, 1980-1986.

García-Fuentes, Lutgardo: Sevilla, los vascos y América, Fundación BBV, Bilbao, 1991.

Hearth-Terré, Emilio: “Los artífices vascos en el Perú Virreinal”, El Comercio, Lima, 1 de septiembre de 1948.

Helmer, Marie: “Un tipo social: 'el minero' de Potosí’, Revista de Indias, XVI, Madrid, 1956, págs. 85-92.

— "Luchas entre vascongados y 'vicuñas' en Potosî́, Revista de Indias, XX, n. ${ }^{\circ}$ 81-82, Madrid, 1960, págs. 185-195.

Legarda, Anselmo de: Lo “vizcaíno" en la literatura castellana, Biblioteca Vascongada de Amigos del País, San Sebastián, 1953.

Leonard, Irving A.: Viajeros por la América Latina colonial, Fondo de Cultura Económica, México, 1992 (primera ed. en inglés en 1972).

Madariaga, Salvador de: Cuadro histórico de las Indias. Introducción a Bolivar, Buenos Aires, 1945. 
Martín, Carmen: "Vascos en Potosí: minas y mineros, según una fuente inédita de Arzáns y Vela", en Álvarez-Gila, Oscar et al. (ed.), Emigración y redes sociales de los vascos en América, Servicio Editorial de la UPV-EHU, Vitoria, 1996, págs. 411-418.

Mendoza, L. Gunnar: Guerra entre vascongados y otras naciones de Potosí, Documentos del Archivo Nacional de Bolivia (1622-1641), Cuadernos de la Cultura Boliviana, Potosí, 1954.

Omiste, Modesto: Crónicas potosinas. Estadísticas, biográficas, notas históricas y políticas, La Paz, 1918 (ahora en El siglo, Potosí, 1981).

Pérez-Alcalá, Rosario: "Vicuñas y vascongados: la lucha por el poder en Potosí en el siglo XVII", Ifigea, V-VI, 1989, págs. 207-215.

Presta, Ana María: Los encomenderos de La Plata, Instituto de Estudios Peruanos, Lima, 2000.

Ruiz de Azúa, Estíbaliz: Vascongadas y América, Colección las Españas y América, Mapfre, Madrid, 1992.

Serrano, Fernando: Vascos y extremeños en el Nuevo Mundo durante el siglo XVII: un conflicto por el poder, Asamblea de Extremadura, Mérida (España), 1993.

Tellechea, Ignacio: Doña Catalina de Erauso. La monja alférez, Sociedad Guipuzcoana de Ediciones y Publicaciones, San Sebastián, 1992.

Vázquez-Machicado, José: Catálogo de documentos referentes a Potosí en el Archivo General de Indias de Sevilla, Editorial Potosí, Potosí, 1964.

Z[aragoza, Justo] (ed.): Castellanos y vascongados. Tratado breve de una disputa y diferencia que hubo entre dos amigos, el uno castellano de Búrgos y el otro vascongado, en la villa de Potosí, reino del Perú, Imprenta á cargo de Víctor Saiz, Madrid, 1876. 